\title{
Corrigendum: Ferritin polarization and iron transport across monolayer epithelial barriers in mammals
}

\author{
Esther G. Meyron-Holtz *, Lyora A. Cohen, Lulu Fahoum, Yael Haimovich, Lena Lifshitz, \\ Inbar Magid-Gold, Tanja Stuemler and Marianna Truman-Rosentsvit \\ Laboratory for Molecular Nutrition, Faculty of Biotechnology and Food Engineering, Technion, Israel Institute of Technology, \\ Haifa, Israel
}

Keywords: iron transport, iron metabolism, epithelial barriers, tight junctions, ferritin polarization

\section{OPEN ACCESS}

Edited by:

Paolo Arosio

University of Brescia, Italy

${ }^{*}$ Correspondence: Esther G. Meyron-Holtz, meyron@tx.technion.ac.il

Specialty section:

This article was submitted to Drug Metabolism and Transport,

a section of the journal

Frontiers in Pharmacology

Received: 14 July 2015

Accepted: 21 July 2015

Published: 06 August 2015

Citation:

Meyron-Holtz EG, Cohen LA, Fahoum L, Haimovich Y, Lifshitz L, Magid-Gold

I, Stuemler $T$ and Truman-Rosentsvit M (2015) Corrigendum: Ferritin polarization and iron transport across monolayer epithelial barriers in mammals. Front. Pharmacol. 6:163. doi: 10.3389/fphar.2015.00163

\section{A Corrigendum on}

Ferritin polarization and iron transport across monolayer epithelial barriers in mammals by Meyron-Holtz, E. G., Cohen, L. A., Fahoum, L., Haimovich, Y., Lifshitz, L., Magid-Gold, I., et al. (2014). Front. Pharmacol. 5:194. doi: 10.3389/fphar.2014.00194

On the original article the acknowledgment section was missing a funding source. The correct and updated acknowledgments are below.

\section{Acknowledgments}

This format of Perspective is limited to 3000 words and we apologize to all researchers whose original work had to be cited through reviews. We thank Prof. Kenneth Tung for critical reading of the manuscript and Joshua Dunaief for sharing his pictures from the retina. This work was funded by the US-Israel Binational Science Foundation, Grant no. 2007466 to EM and Tracey A. Rouault and by a grant of the Israel Science Foundation, Grant no. 2019950 to EM.

Conflict of Interest Statement: The authors declare that the research was conducted in the absence of any commercial or financial relationships that could be construed as a potential conflict of interest.

Copyright (®) 2015 Meyron-Holtz, Cohen, Fahoum, Haimovich, Lifshitz, Magid-Gold, Stuemler and Truman-Rosentsvit. This is an open-access article distributed under the terms of the Creative Commons Attribution License (CC BY). The use, distribution or reproduction in other forums is permitted, provided the original author(s) or licensor are credited and that the original publication in this journal is cited, in accordance with accepted academic practice. No use, distribution or reproduction is permitted which does not comply with these terms. 